\title{
Peptide self-assembly into lamellar phases and the formation of lipid-peptide nanostructures
}

\author{
Karin Kornmueller ${ }^{1}$, Bernhard Lehofer ${ }^{1}$, Gerd Leitinger ${ }^{2}$, Heinz Amenitsch ${ }^{3}$, and Ruth Prassl $^{1}(\varangle)$ \\ ${ }^{1}$ Institute of Biophysics, Medical University of Graz, BioTechMed-Graz, Graz 8010, Austria \\ ${ }^{2}$ Institute of Cell Biology, Histology and Embryology, Research Unit Electron Microscopic Techniques, Medical University of Graz, Graz \\ 8010, Austria \\ ${ }^{3}$ Institute of Inorganic Chemistry, Graz University of Technology, Graz 8010, Austria
}

\author{
Received: 17 March2017 \\ Revised: 7 June2017 \\ Accepted: 8 June 2017 \\ (C) The author(s) 2017. This \\ article is published with open \\ access at link.Springer.com

\section{KEYWORDS} \\ amphiphilic designer \\ peptides, \\ lipids, \\ nanostructures, \\ lamellae, \\ small-angle X-ray \\ scattering (SAXS), \\ transmission electron \\ microscopy (TEM)
}

\begin{abstract}
Lipids exhibit an extraordinary polymorphism in self-assembled mesophases, with lamellar phases as the most relevant biological representative. To mimic lipid lamellar phases with amphiphilic designer peptides, seven systematically varied short peptides were engineered. Indeed, four peptide candidates $\left(\mathrm{V}_{4} \mathrm{D}\right.$, $\mathrm{V}_{4} \mathrm{WD}, \mathrm{V}_{4} \mathrm{WD}_{2}, \mathrm{I}_{4} \mathrm{WD}_{2}$ ) readily self-assembled into lamellae in aqueous solution. Small-angle X-ray scattering (SAXS) patterns revealed ordered lamellar structures with a repeat distance of $\sim 4-5 \mathrm{~nm}$. Transmission electron microscopy (TEM) images confirmed the presence of stacked sheets. Two derivatives $\left(\mathrm{V}_{3} \mathrm{D}\right.$ and $\left.\mathrm{V}_{4} \mathrm{D}_{2}\right)$ remained as loose aggregates dispersed in solution; one peptide $\left(\mathrm{L}_{4} \mathrm{WD}_{2}\right)$ formed twisted tapes with internal lamellae and an antiparallel $\beta$-type monomer alignment. To understand the interaction of peptides with lipids, they were mixed with phosphatidylcholines. Low peptide concentrations $(1.1 \mathrm{mM})$ induced the formation of a heterogeneous mixture of vesicular structures. Large multilamellar vesicles (MLV, $d$-spacing $\sim 6.3 \mathrm{~nm}$ ) coexisted with oligo- or unilamellar vesicles ( $50 \mathrm{~nm}$ in diameter) and bicelle-like structures ( $45 \mathrm{~nm}$ length, $\sim 18 \mathrm{~nm}$ width). High peptide concentrations $(11 \mathrm{mM}$ ) led to unilamellar vesicles (ULV, diameter $\sim 260-280 \mathrm{~nm}$ ) with a homogeneous mixing of lipids and peptides. SAXS revealed the temperature-dependent fine structure of these ULVs. At $25^{\circ} \mathrm{C}$ the bilayer is in a fully interdigitated state (headgroup-to-headgroup distance $d_{\mathrm{HH}} \sim 2.9 \mathrm{~nm}$ ), whereas at $50{ }^{\circ} \mathrm{C}$ this interdigitation opens up $\left(d_{\mathrm{HH}} \sim 3.6 \mathrm{~nm}\right)$. Our results highlight the versatility of self-assembled peptide superstructures. Subtle changes in the amino acid composition are key design elements in creating peptide- or lipidpeptide nanostructures with richness in morphology similar to that of naturally occurring lipids.
\end{abstract}

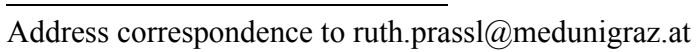




\section{Introduction}

The remarkable ability of phospholipids to selfassemble into various lamellar structures is essential for life, as they create the fundamental structural component of biological membranes [1-5]. Lipid-like designer peptides are promising candidates to mimic this feature. A fundamental characteristic is their amphiphilicity, which derives from an antagonistic arrangement of charged (hydrophilic) amino acids and hydrophobic tail residues [6]. Above a critical aggregation concentration (CAC), amphiphiles selfassemble into supramolecular structures similar to lipid mesophases. Several one-dimensional (1D) and two-dimensional (2D) structures have been reported, including micelles, cylinders, and lamellar or hexagonal phases [6-17]. Not only do peptides structurally resemble lipid molecules, but they also exhibit similar surfactant-like properties. Several earlier studies focused on their application as surfactants in membrane protein stabilization [18-23]. Their use as antimicrobial agents has also been considered [24, 25]. Recently, peptide vesicles were tested for their capability as drug- or gene-delivery systems [26-29] or as bioactive scaffolds in tissue engineering applications [30-32]. All applications involve peptides either mimicking lipid molecules or coming in close contact with biological lipid membranes.

We therefore aimed to relate those features that make amphiphilic designer peptides "lipid-like" to their selfassembling behavior. We intended to create peptidebased lamellar phases and study how peptides react upon interaction with lipid systems. In order to achieve this, we recently investigated the self-assembly and lipid-interaction propensity of two short amphiphilic designer peptides $\left(\mathrm{V}_{4} \mathrm{WD}_{2}\right.$ and $\left.\mathrm{A}_{6} \mathrm{YD}\right) . \mathrm{V}_{4} \mathrm{WD}_{2}$ has shown a high propensity to interact with artificial as well as biological membrane systems [33]. In the present work we attempted to gain a better understanding of which features of the peptide sequence are critical for self-assembly and what drives the interaction with membranes by combining information from smallangle $\mathrm{X}$-ray scattering (SAXS), transmission electron microscopy (TEM), and attenuated total reflection Fourier-transform infrared spectroscopy (ATR-FTIR). We systematically designed six derivatives of the peptide $\mathrm{V}_{4} \mathrm{WD}_{2}$ (Fig. 1). In particular, three regions of

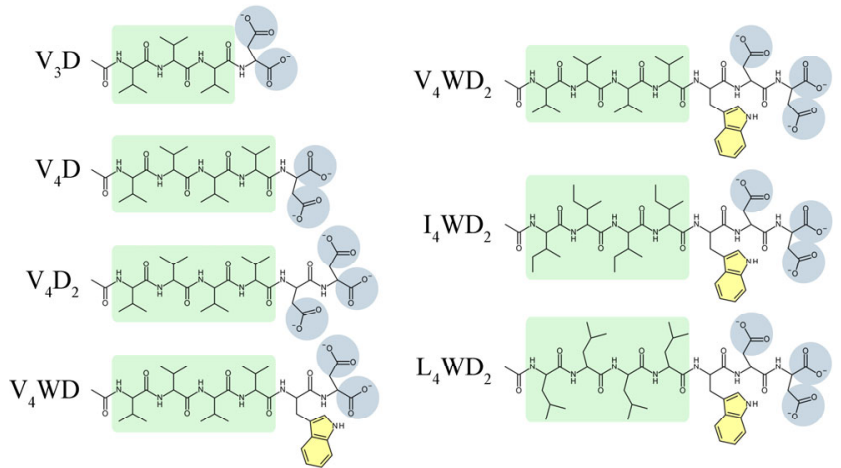

Figure 1 Molecular structures of the 7 investigated amphiphilic designer peptides. All peptides are acetylated at their N-terminus. The hydrophobic parts of the molecules are highlighted in green; tryptophan residues are shown in yellow; and residues that are charged at $\mathrm{pH} 7$ are labeled blue.

the peptide were modified. First, the hydrophobicity level was varied by replacing the four hydrophobic valine tail residues with either leucine or isoleucine. Second, the influence of tryptophan was investigated by comparing $\mathrm{V}_{4} \mathrm{WD}_{2}$ and $\mathrm{V}_{4} \mathrm{WD}$ to their tryptophanlacking derivatives. Third, by varying the number of charged headgroup residues and by designing the extremely short peptide $\mathrm{V}_{3} \mathrm{D}$, we aimed to elucidate the influence of hydrophile:lipophile ratio and peptide length. A list of all peptides and their physicochemical characteristics is provided in Table 1. By addressing the influence of systematical changes in the amino acid composition, we found relationships between details at the molecular level and both peptide structure development and lipid-peptide interactions. We demonstrate that subtle changes in peptide sequence can be utilized as key design elements to create a diversity of peptide- or lipid-peptide nanostructures.

\section{Experimental}

\subsection{Chemicals}

The amphiphilic designer peptides ac $-\mathrm{V}_{3} \mathrm{D}$, ac $-\mathrm{V}_{4} \mathrm{D}$, ac $-\mathrm{V}_{4} \mathrm{D}_{2}$, ac- $\mathrm{V}_{4} \mathrm{WD}_{2}$, ac- $\mathrm{V}_{4} \mathrm{WD}$, ac- $\mathrm{I}_{4} \mathrm{WD}_{2}$, and ac- $\mathrm{L}_{4} \mathrm{WD}_{2}$ were custom synthesized and purified by Peptide 2.0 (Chantilly, VA, USA). Dipalmitoyl phosphatidylcholine (DPPC) was purchased from Avanti Polar Lipids (Alabaster, AL, USA). All other chemicals were purchased either from Sigma-Aldrich (Vienna, Austria) or Carl Roth $\mathrm{GmbH}$ (Karlsruhe, Germany) and were of analytical grade. 
Table 1 Summary of the 7 investigated peptides and their chemical characteristics

\begin{tabular}{cccccc}
\hline & Number of amino acids & Charge at $\mathrm{pH} 7$ & $M_{\mathrm{W}}(\mathrm{g} / \mathrm{mol})$ & Hydrophobicity $(\mathrm{kcal} / \mathrm{mol})[34,35]$ & $\sim \mathrm{CAC}(\mathrm{mM})$ \\
\hline $\mathrm{V}_{3} \mathrm{D}$ & 4 & -2 & 475.5 & +10.16 & $>>20$ \\
$\mathrm{~V}_{4} \mathrm{D}$ & 5 & -2 & 571.7 & +9.70 & $>2$ \\
$\mathrm{~V}_{4} \mathrm{D}_{2}$ & 6 & -3 & 686.8 & +13.34 & n.d. $^{\text {b }}$ \\
$\mathrm{V}_{4} \mathrm{WD}$ & 6 & -2 & 757.9 & +7.61 & 4.8 \\
$\mathrm{~V}_{4} \mathrm{WD}_{2}$ & 7 & -3 & 873.0 & +11.25 & 7.5 \\
$\mathrm{I}_{4} \mathrm{WD}_{2}$ & 7 & -3 & 929.1 & +8.61 & 4.1 \\
$\mathrm{~L}_{4} \mathrm{WD}_{2}$ & 7 & -3 & 929.1 & +8.09 & 1.9 \\
\hline
\end{tabular}

${ }^{\mathrm{a}}$ The CAC was determined by fluorescence spectroscopy (Fig. S1 in the ESM).

${ }^{\mathrm{b}}$ This peptide does not form supramolecular assemblies and did not show a fluorescence signal over the investigated concentration regime.

\subsection{Peptide sample preparation}

Samples were prepared by mixing the lyophilized peptide with double-distilled water and by a stepwise addition of $1 \mathrm{M}$ or $0.1 \mathrm{M} \mathrm{NaOH}$ until the samples appeared as clear, colorless solutions. Concentrations ranged from $0.1-75 \mathrm{mM}$ with resulting $\mathrm{pH}$ values between 9 and 12. Samples were left to equilibrate at 20-25 ${ }^{\circ} \mathrm{C} 1$ week prior to CAC determination (Fig. S1 in the Electronic Supplementary Material (ESM)), SAXS, ATR-FTIR, and TEM measurements.

\subsection{Calculating the peptide average hydrophobicity}

To calculate a peptide's overall hydrophobicity, a decision has to be made regarding the hydrophobicity scale to be used. Several different scales are used [36]; however, owing to different experimental or calculation approaches, they are comparable only to a certain extent. With respect to subsequent peptide-lipid partitioning experiments, we decided to use the Wimley-White whole-residue scale [34] for our peptides (see Table 1).

\subsection{Preparation of lipid-peptide mixed systems}

DPPC was dissolved in chloroform/methanol $(2: 1 \mathrm{v} / \mathrm{v})$ and mixed, and organic solvents were evaporated under a gentle stream of nitrogen, followed by drying under vacuum overnight in order to completely remove residual organic solvents. The dry lipid-film was hydrated by adding either double-distilled water (reference) or freshly prepared aqueous solutions of the peptides to finally obtain two different molar ratios: 50:1 and 5:1 DPPC/peptide ( $\mathrm{mol} / \mathrm{mol})$. These ratios correspond to peptide concentrations of 1.1 and $11 \mathrm{mM}$, with a constant DPPC concentration of $55 \mathrm{mM}$. The samples were incubated above the lipid's phase transition temperature at $50{ }^{\circ} \mathrm{C}$ for $2 \mathrm{~h}$, intermitted by vigorous vortexing every $15 \mathrm{~min}$. Samples were incubated with gentle rotation for $24 \mathrm{~h}$ at room temperature before SAXS and TEM measurements were performed.

\subsection{SAXS}

Synchrotron X-ray scattering data were collected at the Austrian SAXS beamline at ELETTRA (Trieste, Italy) [37]. Measurements were conducted at a wavelength of $0.154 \mathrm{~nm}$ and a sample-detector distance of $1.1 \mathrm{~m}$. The photon energy was $8 \mathrm{keV}$. The X-ray images were recorded with a Pilatus detector (Pilatus3 1M, DECTRIS Ltd., Villigen PSI, Switzerland) calibrated with silver behenate. The scattering intensity was measured as a function of the scattering vector $q$ where

$$
q=4 \pi(\sin \theta) / \lambda
$$

with $2 \theta$ being the scattering angle and $\lambda$ being the wavelength. Samples were measured in a $1.5-\mathrm{mm}$ glass capillary. Data analysis was done with Fit2D [38] and Igor Pro (Version 6.22A, WaveMetrics Inc., Portland, OR, USA). Experimental intensities were background corrected, and absolute calibration was performed with water as the secondary standard using the method described by Orthaber [39].

\subsubsection{SAXS data analysis of pure peptide structures}

(a) Power law of the initial slope

In a double logarithmic plot, the slope of the form factor at small angles (Guinier regime) allows for a rough 
classification into globular $\left(q^{-0}\right)$, cylindrical $\left(q^{-1}\right)$, or lamellar $\left(q^{-2}\right)$ shapes. The power law of the form factor in the linear region was determined from the $75-\mathrm{mM}$ peptide scattering profiles between $q=0.1$ and $0.25 \mathrm{~nm}^{-1}$.

(b) Determination of the lamellar spacing

Many of the scattering curves contained quasi-Bragg peaks. The lamellar spacing $d$ was determined by

$$
d=2 \pi h / q(h)
$$

where $h$ is the diffraction order and $q(h)$ is the respective position of the peak maximum.

\subsubsection{SAXS data analysis of lipid-peptide binary mixtures}

The following form factor and structure factor models were applied:

(a) Bilayer form factor model

Samples with no positional correlation $\left(50^{\circ} \mathrm{C}\right.$ samples) were fitted with a bilayer form factor model. We used a Gaussian representation of the electron density profile [40,41]. Four parameters had to be adjusted: $z_{\mathrm{H}}$ and $\sigma_{\mathrm{H}}$, the center and width of the headgroup Gaussian respectively; $\sigma_{\mathrm{C}}$ the width of the hydrocarbon chain Gaussian; and $\rho_{\mathrm{R}}$ the ratio of the methyl-terminus electron density amplitude to the headgroup amplitude $\left(\rho_{\mathrm{R}}=\rho_{\mathrm{C}} / \rho_{\mathrm{H}}\right)$.

\section{(b) Structure factors}

Depending on the temperature, two different structure factor models were applied. For samples measured at $25^{\circ} \mathrm{C}$, a paracrystalline theory (PT) structure factor was applied, whereas for $50{ }^{\circ} \mathrm{C}$ samples, a modified Caillé theory (MCT) was used [40,41]. Fitting parameters were as follows: the estimated number of layers within the scattering domain $N$, the lamellar repeat distance $d$, and a model-dependent disorder parameter, i.e., either the mean square fluctuations of the bilayer $\Delta(\mathrm{PT})$ or the Caillé parameter $\eta(\mathrm{MCT})$.

\subsection{ATR-FTIR spectroscopy}

Infrared spectra were recorded between 4,000 and $600 \mathrm{~cm}^{-1}$ on a Bruker ALPHA-T FTIR spectrometer equipped with an ATR accessory (Bruker Optics Inc., Billerica, MA, USA). The spectra were the averages of 128 scans with a resolution of $4 \mathrm{~cm}^{-1}$. Spectra were water corrected, and data analysis was done with OPUS
(Bruker Optics Inc.) and Igor Pro (Version 6.22A, WaveMetrics Inc.).

\subsection{Negative staining TEM}

Samples were dropped onto a glow-discharged carboncoated copper grid and allowed to settle for $1 \mathrm{~min}$. Excess fluid was carefully removed with filter paper and immediately replaced by $5 \mu \mathrm{L}$ of a $2 \%(\mathrm{w} / \mathrm{v})$ uranyl acetate staining solution, which was centrifuged for $6 \mathrm{~min}$ at 10,000 rpm prior to usage in order to precipitate potentially present aggregates. The uranyl acetate solution was allowed to settle for $30 \mathrm{~s}$, blotted, and replaced by another $5 \mu \mathrm{L}$ of fresh solution. After $30 \mathrm{~s}$ of incubation, the staining solution was removed, and the samples were air-dried. Visualization of the samples was achieved with a Fei Tecnai $G^{2} 20$ transmission electron microscope (Eindhoven, the Netherlands) operating at an acceleration voltage of $120 \mathrm{kV}$. Digital images were acquired using a Gatan US1000 CCD camera at $2 \mathrm{k} \times 2 \mathrm{k}$ resolution and the Digital Micrograph software (Version 1.93.1362, Gatan Inc., Pleasanton, CA, USA). Brightness and contrast were adjusted globally.

\section{Results}

\subsection{Structural characterization of self-assembled pure peptide structures ( $75 \mathrm{mM}$ samples)}

To study whether the designed amphiphilic designer peptides are capable of forming lamellar structures, their self-assembling behavior was investigated at extremely high peptide concentrations. Peptides were prepared as $75 \mathrm{mM}$ samples, as structural details at this concentration usually appear very pronounced, yet the samples remain in their liquid phase and do not display gel-like characteristics. Figure 2 reveals that all investigated samples can be roughly divided into three classes: (1) peptides that show no superstructural features, (2) peptides with pronounced lamellar characteristics, including an inter-lamellar structure factor, and (3) one peptide with a combination of lamellar and tape-like characteristics.

More precisely, (1) two peptides $\left(\mathrm{V}_{3} \mathrm{D}\right.$ and $\left.\mathrm{V}_{4} \mathrm{D}_{2}\right)$ did not self-assemble into ordered structures, even at those high peptide concentrations. The SAXS patterns 


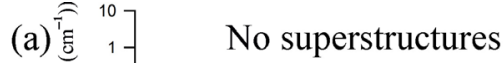

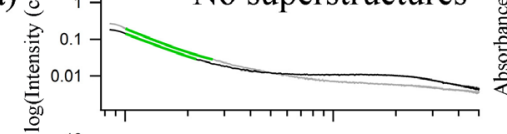

(b)

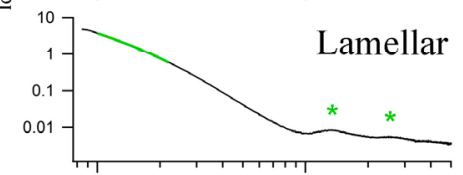

(c)

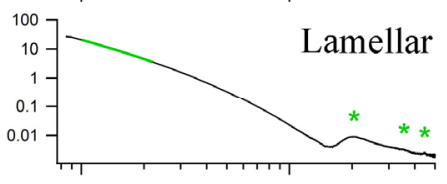

(d)

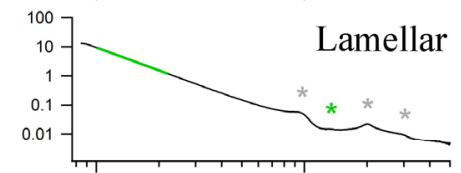

(e)

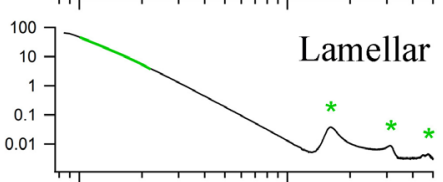

(f)
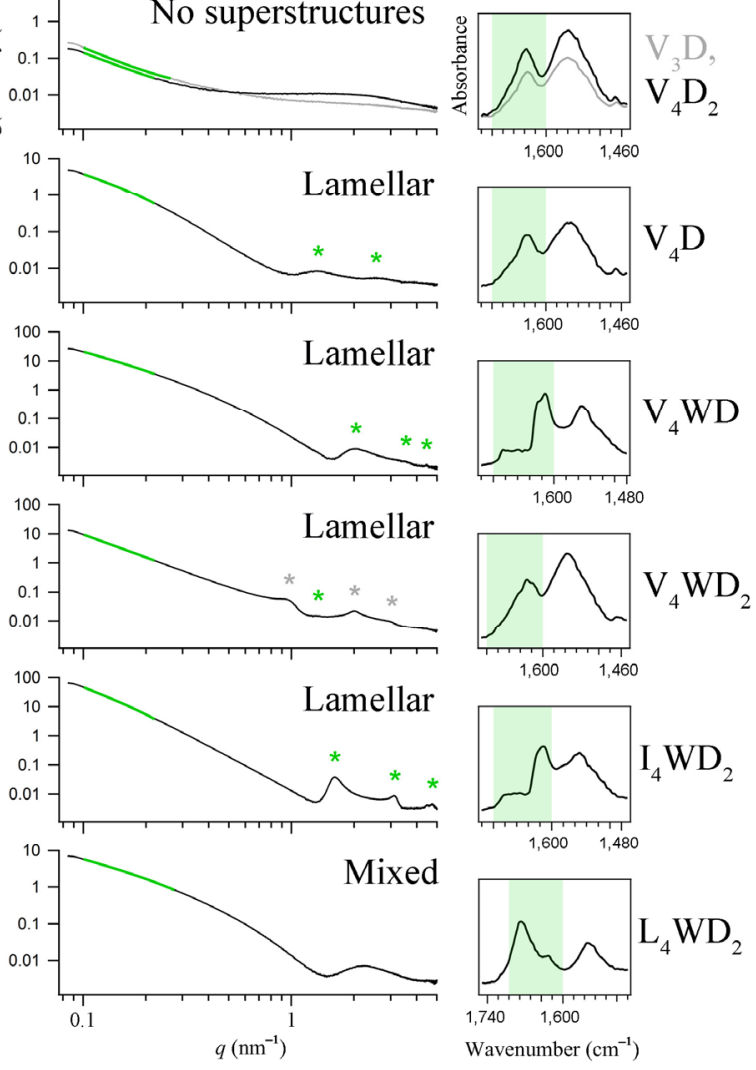

Figure 2 Supramolecular structure formation. The SAXS patterns (left panel) highlight fits of the initial slopes (green curves) and the positions of the lamellar peaks (green and grey asterisks). ATR-FTIR spectra (right panel) show the amide I regions in light green. $\mathrm{V}_{3} \mathrm{D}$ and $\mathrm{V}_{4} \mathrm{D}_{2}$ (a) show no supramolecular structures at $75 \mathrm{mM}$. $\mathrm{V}_{4} \mathrm{D}(\mathrm{b}), \mathrm{V}_{4} \mathrm{WD}(\mathrm{c}), \mathrm{V}_{4} \mathrm{WD}_{2}(\mathrm{~d})$, and $\mathrm{I}_{4} \mathrm{WD}_{2}$ (e) all have lamellar characteristics. $\mathrm{L}_{4} \mathrm{WD}_{2}$ (f) shows a slightly different scattering pattern, hinting at a mixed system (likely lamella/tape-like structures). All recorded ATR-FTIR spectra show $\beta$-sheets as their main characteristics. Samples depicted in (a)-(e) most probably contain parallel $\beta$-type structures, whereas (f) shows an antiparallel arrangement.

showed a very moderate rise in intensity at low $q$-values, which indicates the onset of peptide aggregation (Fig. 2(a)). ATR-FTIR data showed $\beta$-sheet characteristics (amide I peak at 1,635 $\mathrm{nm}^{-1}$ ), which suggests some degree of order, but not on a long-range scale. (2) The majority of peptides $\left(\mathrm{V}_{4} \mathrm{D}, \mathrm{V}_{4} \mathrm{WD}, \mathrm{V}_{4} \mathrm{WD}_{2}\right.$, and $\left.\mathrm{I}_{4} \mathrm{WD}_{2}\right)$ showed a lamellar arrangement, evident by an initial slope of $q^{-2}$ in the SAXS pattern, and repeating peaks, which indicate quasi-long-range order. The associated $d$-spacing covered a range between 3 and $6 \mathrm{~nm}$ (highlighted with asterisks in Figs. 2(b)-2(e), data in Table 2). All of them showed an ATR-FTIR signal at positions typical for $\beta$-sheet arrangement (Table 2). We therefore assume that the peptides arrange in a parallel way, creating flat sheets with the thickness of only one peptide monomer $(\sim 3 \mathrm{~nm})$ plus its hydration layer. We believe that these sheets then stack into several layers, which results in the regular lamellar spacing observed with SAXS (see schematic representation in Fig. 3(a)).

This behavior could be best visualized for the peptide $\mathrm{I}_{4} \mathrm{WD}_{2}$ (Figs. 2(e), 3(b) and 3(c)). TEM images confirmed the presence of multilayered stacks, where each individual layer was around $4-5 \mathrm{~nm}$ thick. (3) One peptide stood out of the crowd: $\mathrm{L}_{4} \mathrm{WD}_{2}$. It showed a scattering profile that could not be assigned to a classical structure easily. It showed cylindrical characteristics, but at the same time the Guinier region showed features of lamellae. This peptide was also the one with a different ATR-FTIR spectrum. We observed splitting of the amide I peak into two peaks at 1,678 and $1,626 \mathrm{~cm}^{-1}$, which indicates that the peptide assembled into antiparallel $\beta$-type structures (Fig. 2(f)). TEM images revealed twisted tape-like structures (Fig. 4). The majority of structures showed diameters in the range of $14-20 \mathrm{~nm}$. Lengths extended to a few hundred nanometers. A closer look into the individual tapes revealed that they were also internally organized in a lamellar way (Fig. 4(c)).

\subsection{Lipid-peptide interplay induces a variety of nanostructures}

Next, we studied lipid-peptide interplay. For this, we prepared DPPC-peptide binary mixed systems of two different compositions. The DPPC fraction was kept constant $(55 \mathrm{mM})$, whereas peptides were present either in low $(1.1 \mathrm{mM})$ or high $(11 \mathrm{mM})$ concentration. Pure DPPC formed multilamellar vesicles (DPPC MLVs) and served as a reference.

\subsubsection{The impact of low peptide concentrations (1.1 $\mathrm{mM}$ ) on a lipid system}

At concentrations of $1.1 \mathrm{mM}$, all peptides were present in a state below their CAC (see Table 1). Figure 5 clearly shows that different peptides interacted differently with DPPC and that the majority of curves significantly deviated from the pure DPPC reference. The scattering of pure DPPC MLVs showed characteristic Bragg peaks 
Table 2 SAXS parameters and ATR-FTIR peak assignment of $75 \mathrm{mM}$ peptide samples

\begin{tabular}{|c|c|c|c|c|}
\hline $\begin{array}{l}\text { Peptide } \\
(75 \mathrm{mM})\end{array}$ & $\begin{array}{l}\text { SAXS, } \\
\text { initial slope }\end{array}$ & $\begin{array}{l}\text { SAXS, } \\
\text { lamellar spacings }(\mathrm{nm})^{\mathrm{a}}\end{array}$ & ATR-FTIR peaks $\left(\mathrm{cm}^{-1}\right)$ & $\begin{array}{l}\text { ATR-FTIR band } \\
\text { assignment }\end{array}$ \\
\hline $\mathrm{V}_{3} \mathrm{D}$ & -2.5 & - & 1,635 & $\beta$-Sheet \\
\hline$V_{4} D_{2}$ & -2.3 & - & 1,637 & $\beta$-Sheet \\
\hline $\mathrm{V}_{4} \mathrm{D}$ & -1.9 & $4.7,4.7$ & 1,635 & $\beta$-Sheet \\
\hline $\mathrm{V}_{4} \mathrm{WD}$ & -1.9 & $3.1,3.5,4.2$ & $\begin{array}{c}\qquad \begin{array}{c}1,615 \\
1,626\end{array} \\
\text { Plateau }(1,649-1,684)\end{array}$ & $\begin{array}{l}\text { Aggregated strands } \\
\beta \text {-Sheet } \\
\text { Antiparallel } \beta \text {-sheet, loops \& turns }\end{array}$ \\
\hline $\mathrm{V}_{4} \mathrm{WD}_{2}$ & -2.6 & $6.6,4.7,6.3,6.4^{\mathrm{b}}$ & $\begin{array}{l}1,618 \\
1,628\end{array}$ & $\begin{array}{l}\text { Aggregated strands } \\
\beta \text {-Sheet }\end{array}$ \\
\hline $\mathrm{I}_{4} \mathrm{WD}_{2}$ & -2.8 & $3.9,4.0,4.0$ & $\begin{array}{c}1,614 \\
1.622 \\
\text { Plateau }(1,653-1,683)\end{array}$ & $\begin{array}{l}\text { Aggregated strands } \\
\beta \text {-Sheet } \\
\text { Antiparallel } \beta \text {-sheet, loops \& turns }\end{array}$ \\
\hline $\mathrm{L}_{4} \mathrm{WD}_{2}$ & -1.5 & - & $\begin{array}{l}1,678 \\
1,626\end{array}$ & $\begin{array}{l}\text { Antiparallel } \beta \text {-sheet, or turns \& loops } \\
\beta \text {-Sheet }\end{array}$ \\
\hline
\end{tabular}

${ }^{a}$ Lamellar $d$-spacing is derived from the SAXS peaks marked with asterisks in Fig. 2.

${ }^{\mathrm{b}}$ Grey asterisks and $d$-spacing label a second lamellar phase $\left(d_{\mathrm{av}}=6.4 \mathrm{~nm}\right)$, coexisting with the primary lamellar phase $(d=4.7 \mathrm{~nm})$.
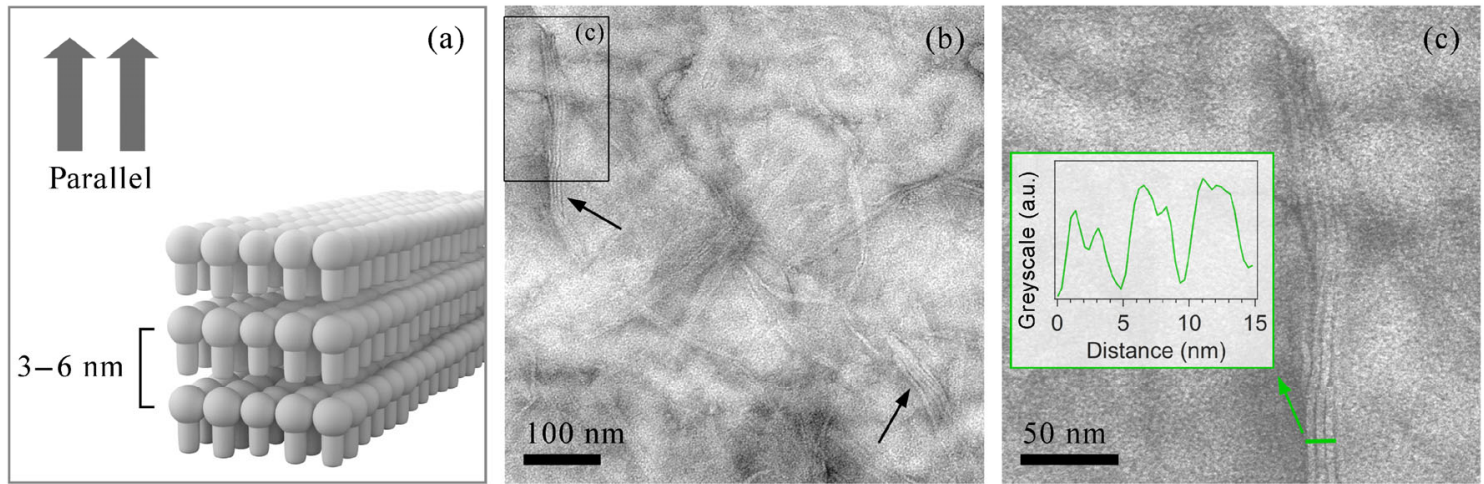

Figure 3 The lamellar arrangement of peptide superstructures. The scheme (a) illustrates the parallel alignment of peptide monomers into flat sheets, which stack into layers. Negative staining TEM images of the self-assembled peptide $\mathrm{I}_{4} \mathrm{WD}_{2}$ at $75 \mathrm{mM}$ (b) and (c) show tapes with lamellar arrangement (black arrows). The line profile in (c) shows distances of 4-5 nm for each lamella.
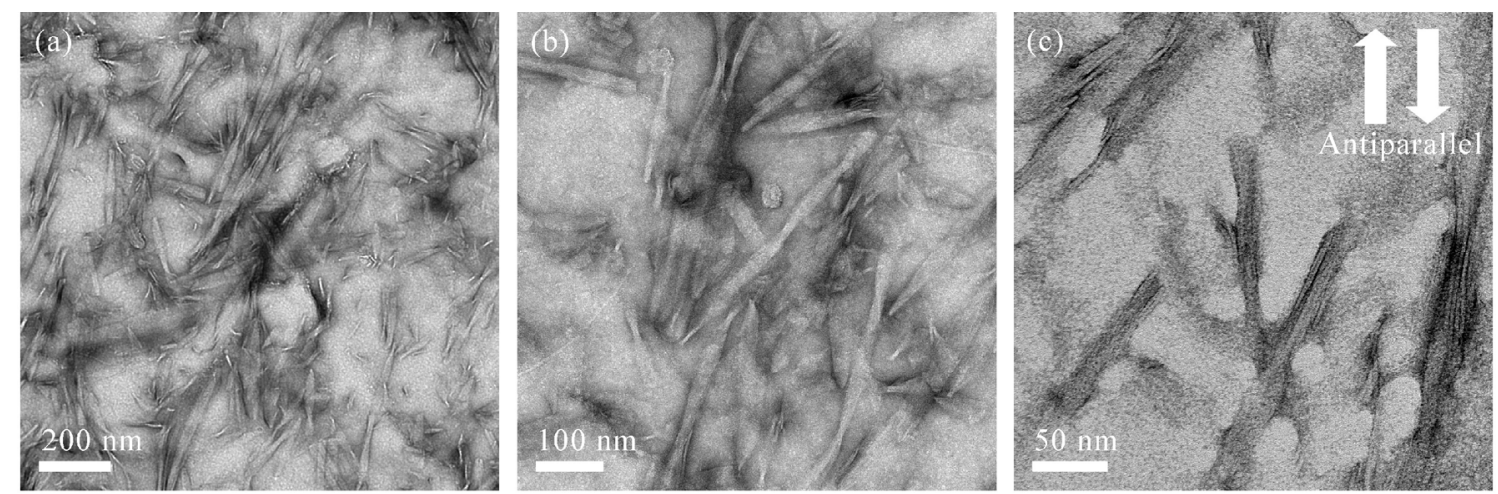

Figure 4 Negative staining TEM images of the self-assembled peptide $\mathrm{L}_{4} \mathrm{WD}_{2}$ (a)-(c). At $75 \mathrm{mM}$, the peptide forms twisted tapes. (c) shows the lamellar internal structure. We assume that monomers are arranged in an antiparallel way (based on ATR-FTIR results). 


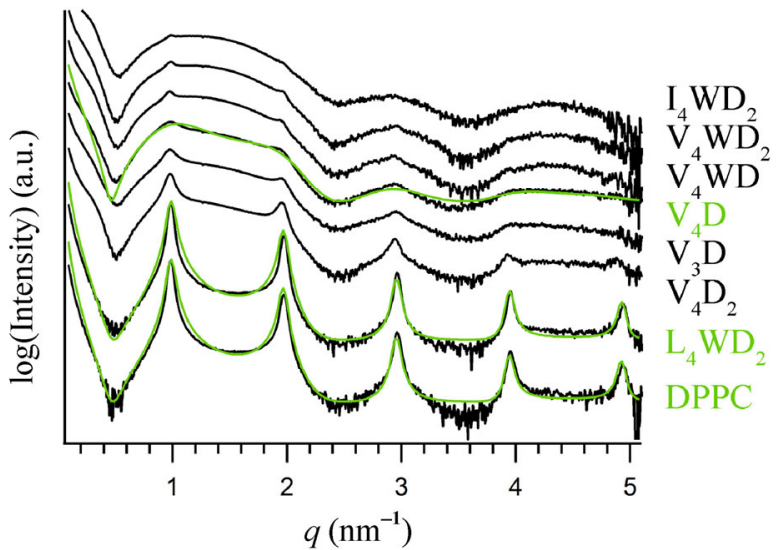

Figure 5 SAXS analysis of DPPC in the presence of $1.1 \mathrm{mM}$ peptide at $25^{\circ} \mathrm{C}$. Pure DPPC and DPPC: $\mathrm{L}_{4} \mathrm{WD}_{2}$ show the same scattering pattern, which is typical for MLVs. All the other peptides show a significant amount of positionally uncorrelated bilayers, with only the signature of DPPC diffraction peaks at their original positions remaining. Black curves are the experimentally obtained scattering patterns; green curves are the respective fits (bilayer form factor model combined with a PT structure factor).

up to the $5^{\text {th }}$ order with a lamellar repeat distance $d$ of $6.38 \mathrm{~nm}$. We could fit the scattering pattern by applying a full $q$-range global fitting model, combining a Gaussian model representation of the bilayer electron density profile with a PT structure factor [40, 41]. The PT structure factor was chosen because at $25^{\circ} \mathrm{C}$ DPPC is in its gel phase and shows a high bending rigidity. All obtained structural parameters are presented in Table 3 and are in accordance with Ref. [42].

Once DPPC is mixed with peptides $(1.1 \mathrm{mM})$, it depends on the peptide sequence whether the multilamellar arrangement is maintained. Only DPPC: $\mathrm{L}_{4} \mathrm{WD}_{2}$

Table 3 Fit results for pure DPPC, DPPC: $\mathrm{L}_{4} \mathrm{WD}_{2}$, and DPPC: $\mathrm{V}_{4} \mathrm{D}$ at low peptide concentrations

\begin{tabular}{cccc}
\hline Parameter & Pure DPPC & DPPC: $\mathrm{L}_{4} \mathrm{WD}_{2}$ & $\mathrm{DPPC}: \mathrm{V}_{4} \mathrm{D}$ \\
\hline$z_{\mathrm{H}}(\mathrm{nm})$ & 2.07 & 2.08 & 2.11 \\
$\sigma_{\mathrm{H}}(\mathrm{nm})$ & 0.3 & 0.3 & 0.3 \\
$\rho_{\mathrm{R}}($ a.u. $)$ & 0.85 & 0.87 & 0.86 \\
$\sigma_{\mathrm{C}}(\mathrm{nm})$ & 0.39 & 0.37 & 0.39 \\
$L_{\mathrm{E}}(\mathrm{nm})$ & 50 & 50 & 3.3 \\
$\Delta(\mathrm{nm})$ & 0.001 & 0.001 & 0.2 \\
$d(\mathrm{~nm})$ & 6.4 & 6.4 & 6.4 \\
$d_{\mathrm{HH}}(\mathrm{nm})$ & 4.1 & 4.2 & 4.2 \\
$d_{\mathrm{B}}(\mathrm{nm})$ & 5.3 & 5.4 & 5.4 \\
$d_{\mathrm{W}}(\mathrm{nm})$ & 1.1 & 1.0 & 1.0 \\
\hline
\end{tabular}

showed the same scattering pattern as pure DPPC and yielded the same structural parameters after fitting (Table 3). The derived electron density profiles of DPPC and $\mathrm{L}_{4} \mathrm{WD}_{2}$ are illustrated in Fig. 6 . The similarity in their profiles might be explained by the fact that $\mathrm{L}_{4} \mathrm{WD}_{2}$ does not interact at all with DPPC molecules. This means that $\mathrm{L}_{4} \mathrm{WD}_{2}$ monomers have a higher affinity toward each other than toward DPPC and thus build a separate phase, coexisting with the DPPC MLVs. However, due to the low peptide concentration, this fraction is almost negligible and not represented in the scattering pattern. Another option might be that the peptide molecules are integrated into the whole lipid system without changing the overall or the fine structure of MLVs.

$\mathrm{L}_{4} \mathrm{WD}_{2}$ is the exception-all the other peptides resulted in a significant disturbance of the DPPC multilamellar arrangement, as can be seen in Fig. 5 . For DPPC mixed with $\mathrm{V}_{3} \mathrm{D}, \mathrm{V}_{4} \mathrm{D}, \mathrm{V}_{4} \mathrm{D}_{2}, \mathrm{~V}_{4} \mathrm{WD}, \mathrm{V}_{4} \mathrm{WD}_{2}$ and $\mathrm{I}_{4} \mathrm{WD}_{2}$, Bragg peaks were dramatically reduced to only the signatures of quasi-Bragg reflections. In return, the contribution of diffuse scattering was increased, which suggests that the positional correlations between the layers were lost. This goes in line with the observation that the estimated average domain size $\left(L_{\mathrm{E}}\right)$ decreased. It happens when the number of

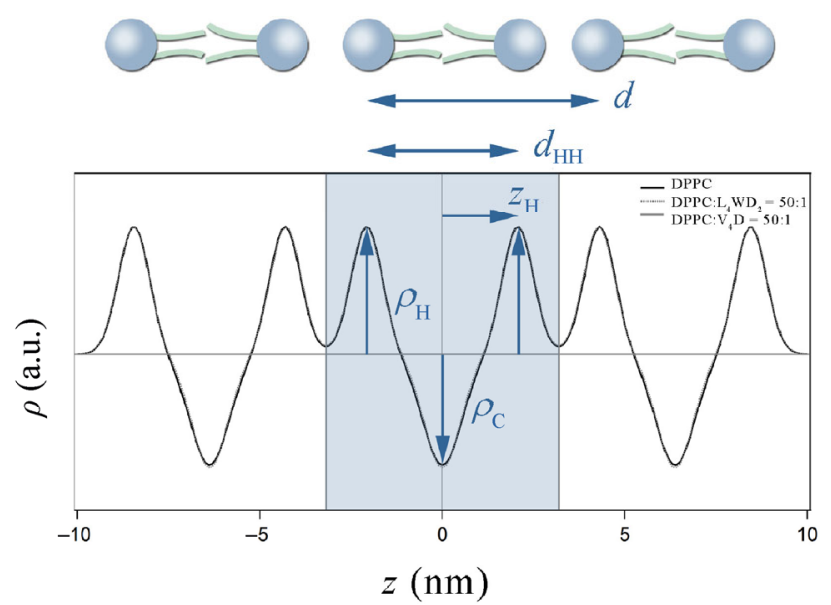

Figure 6 Modulation of the electron density across the bilayer. The profiles of pure DPPC, DPPC: $\mathrm{L}_{4} \mathrm{WD}_{2}$, and DPPC: $\mathrm{V}_{4} \mathrm{D}$ are superimposable. The light blue area shows the basic structure of one bilayer. In the case of multilamellar structures, this basic building block is repeated. The peaks $\left(\rho_{\mathrm{H}}\right)$ at the positions $\pm z_{\mathrm{H}}$ represent the high electron density of the phosphate groups in DPPC, whereas the central Gaussian $\left(\rho_{\mathrm{C}}\right)$ represents the hydrocarbon chain region. 
layers is reduced or the number of defects within the bilayers increase. In addition, the mean square fluctuation of the bilayer $(\Delta)$ increases when set in reference to pure DPPC. DPPC: $\mathrm{V}_{4} \mathrm{D}$ was chosen as a representative example for fitting, because it takes a central position among all investigated samples. Fitting results are presented in Table 3. Altogether we only observed changes in the parameters that refer to the structure factor $\left(L_{\mathrm{E}} \& \Delta\right)$, whereas parameters describing the bilayer form factor did not change $\left(z_{\mathrm{H}}, \sigma_{\mathrm{H}}, \sigma_{\mathrm{C}}\right.$ and $\rho_{\mathrm{R}}$ ). We conclude that the bilayer structure of the membrane remained, but the positional correlation between the individual bilayers changed. Subtle differences could be observed in the group of peptides that contain tryptophan residues versus the ones without. Peptides with tryptophan $\left(\mathrm{I}_{4} \mathrm{WD}_{2}, \mathrm{~V}_{4} \mathrm{WD}_{2}\right.$, $\mathrm{V}_{4} \mathrm{WD}$ ) showed more distinctive trends toward a unilamellar arrangement than the others. In contrast, peptides without tryptophan $\left(\mathrm{V}_{4} \mathrm{D}, \mathrm{V}_{3} \mathrm{D}\right.$, and $\left.\mathrm{V}_{4} \mathrm{D}_{2}\right)$ showed a plateau at $q=1.1-1.8 \mathrm{~nm}^{-1}$. This plateau can be attributed to unspecific assemblies, and an exact assignment was not possible. SAXS analysis did not allow us to draw sophisticated conclusions on the origin of the large diffuse scattering contribution we observed in all samples, except DPPC: $\mathrm{L}_{4} \mathrm{WD}_{2}$. We therefore picked DPPC: $\mathrm{V}_{4} \mathrm{D}$ again to perform a detailed TEM characterization. As can be seen in Fig. 7, TEM revealed a surprisingly heterogeneous mixture, nevertheless with three very well-defined main components: first, large quasi-spherical structures confined by lamellae (labeled Lam). We attribute these structures to the original fraction of MLVs (Fig. 7(a)). The lamellae were highly ordered, with the majority of diameters between 4.6 and $4.8 \mathrm{~nm}$ (statistical analysis is provided in Fig. S2 (in the ESM). Second, small vesicles (V) that showed a clearly defined spherical shape but were significantly smaller than MLVs were detected (Fig. 7(b)). The diameters of these vesicles ranged from as small as 30 to $200 \mathrm{~nm}$ and even larger, but the majority lied between $45-50 \mathrm{~nm}$ (Fig. S3 in the ESM). Steric considerations suggest that these vesicles contained a limited number of bilayers, and thus they explain the origin of the large diffuse scattering contribution in SAXS. Most surprisingly, we found another fraction of structures, which was highly defined and present in large amounts throughout the sample: bicelles (Fig. 7(b), labeled Bc). They exhibited a diskshaped morphology, with lengths of $42-46 \mathrm{~nm}$ and widths around $18 \mathrm{~nm}$ (Figs. S4 and S5 in the ESM). The conventional way to prepare bicelles is by mixing long- and short-chain lipids [43]. We believe that in our case the peptides took over the task of short-chain lipids. One sterically possible conformation is presented in Fig. 7(c).

\subsubsection{The impact of high peptide concentrations (11 $\mathrm{mM}$ )} on a lipid system

Samples with a peptide concentration of $11 \mathrm{mM}$ contained peptides above their CAC, except for $\mathrm{V}_{3} \mathrm{D}$ and $\mathrm{V}_{4} \mathrm{D}_{2}$, which were shown to remain in their monomeric state even at very high peptide concentrations (see Fig. 2). Thus, for all the other peptides, we expect not only a contribution from lipids but also from supramolecular peptide assemblies. Indeed, when
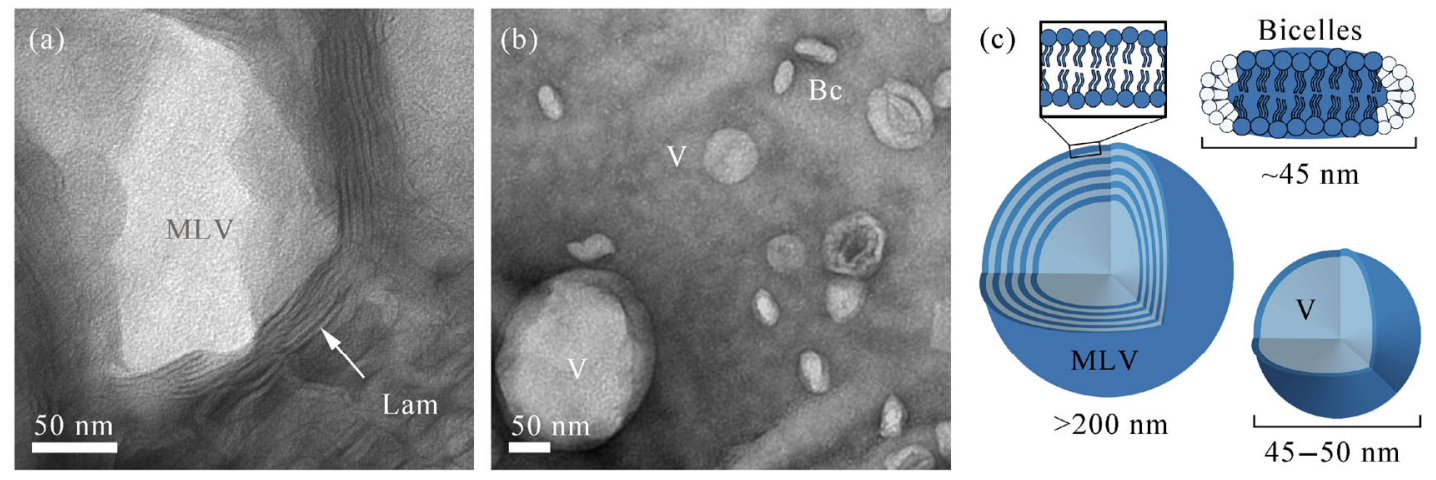

Figure 7 TEM images of DPPC in the presence of $1.1 \mathrm{mM} \mathrm{V}_{4} \mathrm{D}$. The sample shows a high heterogeneity: (a) demonstrates the regular arrangement of lamellae (Lam) within MLVs, and (b) reveals the presence of smaller vesicles (V) and bicelles (Bc). (c) shows a schematic summary of the observed morphologies and their approximate size regimes.

TSIVERITY PRESS 
investigating the DPPC: $\mathrm{V}_{4} \mathrm{D}$ mixture, TEM confirmed the presence of self-assembled supramolecular peptide structures. As can be seen in Fig. $8(\mathrm{a}), \mathrm{V}_{4} \mathrm{D}$ assembled into long tapes, where $2-5$ single tapes were frequently aligned in a parallel way to compose even larger structures (similar to pure $\mathrm{V}_{4} \mathrm{D}$ superstructures, as can be seen in Fig. S6 in the ESM). Single tapes showed diameters of $50-60 \mathrm{~nm}$ and extended to several micrometers in length. A closer look into one single tape (Fig. 8(b)) revealed a layered arrangement also on a smaller scale: Approximately 6 parallel-aligned layers comprised one single tape, with each individual layer being around $15 \mathrm{~nm}$ in width. Obscured by this network of supramolecular tapes laid a different kind of nanostructure, which appeared very crowded in the original sample (Fig. 8(a)) but revealed its full quality in a 1:10 dilution (Fig. 8(c)). Morphologically highly homogeneous spherical structures were observed, with their appearance resembling classical lipid ULVs. The majority of vesicles showed diameters of $260-280 \mathrm{~nm}$ (Fig. S7 in the ESM). This indicates that the original multilamellar DPPC lipid system experienced dramatic morphological changes in the presence of the peptide $\mathrm{V}_{4} \mathrm{D}$. It can be understood that this behavior is not restricted solely to $\mathrm{V}_{4} \mathrm{D}$ when looking at the SAXS patterns of all 7 investigated peptides (Fig. 9). Depending on peptide sequence and temperature, we observed different types of patterns. Therefore, in a next step we aimed to obtain information on the internal organization of the vesicles by analyzing the SAXS patterns with respect to two different temperatures: $25^{\circ} \mathrm{C}$ (below the lipid's phase transition temperature) and $50{ }^{\circ} \mathrm{C}$ (above the lipid's phase transition temperature).

\subsubsection{SAXS analysis of lipid:peptide mixed systems at} high peptide concentrations (11 $\mathrm{mM}$ ) and $25^{\circ} \mathrm{C}$

All samples exhibited scattering curves largely distinct from pure DPPC MLVs (Fig. 9). They showed the general characteristics of positionally uncorrelated bilayers, most likely ULVs. In addition, we observed the emergence of a new lamellar phase in almost all samples. The amplitudes of these peaks were quite weak, suggesting that only a very limited fraction of the sample exhibits this shape. However, the lamellar spacing was well conserved throughout the different samples $(d=4.48 \mathrm{~nm})$. In general, the scattering curves could be again divided into three main classes, which only partly overlapped with the three classes we observed when investigating pure peptide structures (which were: (1) no superstructures, (2) lamellar structures, and (3) twisted tape superstructures). First, we would like to have a closer look at the class comprising $\mathrm{V}_{4} \mathrm{D}, \mathrm{V}_{4} \mathrm{WD}, \mathrm{V}_{4} \mathrm{WD}_{2}$, and $\mathrm{V}_{4} \mathrm{D}_{2}$. TEM revealed the presence of vesicular structures in DPPC: $\mathrm{V}_{4} \mathrm{D}$. In accordance with this, the corresponding scattering curve could be fitted to a ULV model by using a single bilayer electron density model (see Fig. 10). Compared with pure DPPC, DPPC: $\mathrm{V}_{4} \mathrm{D}$ showed a significantly reduced headgroup-to-headgroup distance $\left(d_{\mathrm{HH}}\right)$. The $\rho_{\mathrm{R}}$ and $\sigma_{\mathrm{C}}$ values, which are associated with the tail region, also experienced a significant change (Table 4). The electron density profile shown in Fig. 10 reveals
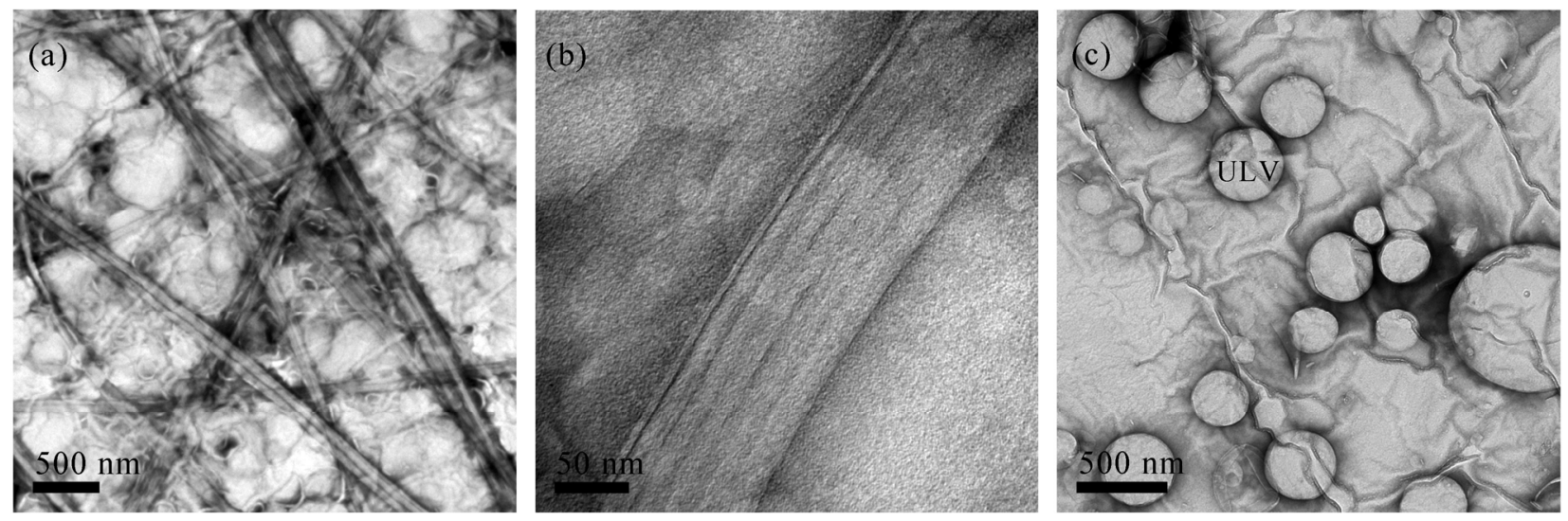

Figure 8 TEM images of DPPC in the presence of $11 \mathrm{mM} \mathrm{V}_{4} \mathrm{D}$. The peptide forms long tubes (a), which are composed of layered structures (b). As soon as the sample is diluted below the peptide's CAC, the vesicular structures come to the fore (c). Their appearance resembles classical ULVs. 


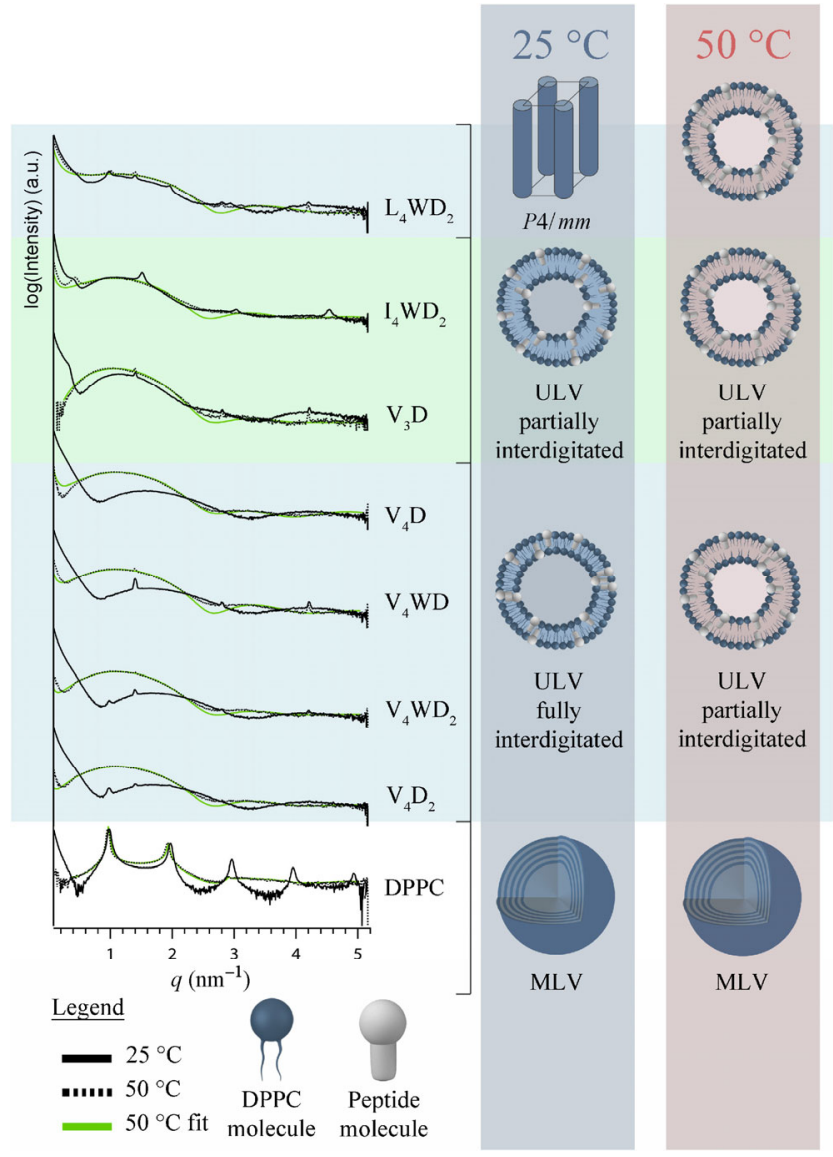

Figure 9 Summary of peptide-membrane interactions at high peptide concentrations. SAXS patterns of DPPC in the presence and absence of $11 \mathrm{mM}$ peptide were investigated. The black solid curves represent the experimentally obtained scattering pattern at $25{ }^{\circ} \mathrm{C}$; the black dotted curves were measured at $50{ }^{\circ} \mathrm{C}$; and the green curves highlight the fits of the $50{ }^{\circ} \mathrm{C}$ samples. Fitting was achieved by using a bilayer form factor model. For pure DPPC, an additional MCT structure factor was added. At $25^{\circ} \mathrm{C}$, results allow a rough classification into three different classes: first, peptides that induce the formation of fully interdigitated ULVs $\left(\mathrm{V}_{4} \mathrm{D}, \mathrm{V}_{4} \mathrm{WD}, \mathrm{V}_{4} \mathrm{WD}_{2}\right.$, and $\left.\mathrm{V}_{4} \mathrm{D}_{2}\right)$. Second, peptides that induce the formation of ULVs with partially interdigitated, partially non-interdigitated characteristics $\left(\mathrm{V}_{3} \mathrm{D}\right.$ and $\left.\mathrm{I}_{4} \mathrm{WD}_{2}\right)$. Third, $\mathrm{L}_{4} \mathrm{WD}_{2}$ that most probably assembles into cylinders in the presence of DPPC with $2 \mathrm{D}$ packing into a squared lattice. At $50{ }^{\circ} \mathrm{C}$, all samples exhibit similar ULV characteristics.

the origin of these changes: The peptide induced the formation of an interdigitated phase. Because $d_{\mathrm{HH}}$ was only $2.9 \mathrm{~nm}$, and peptides as well as DPPC molecules were in the same order of magnitude, we hypothesize that the bilayer was fully interdigitated. This means that the terminal methyl groups of DPPC are located in close proximity to the polar interface of the opposite membrane's leaflet [44]. The second class

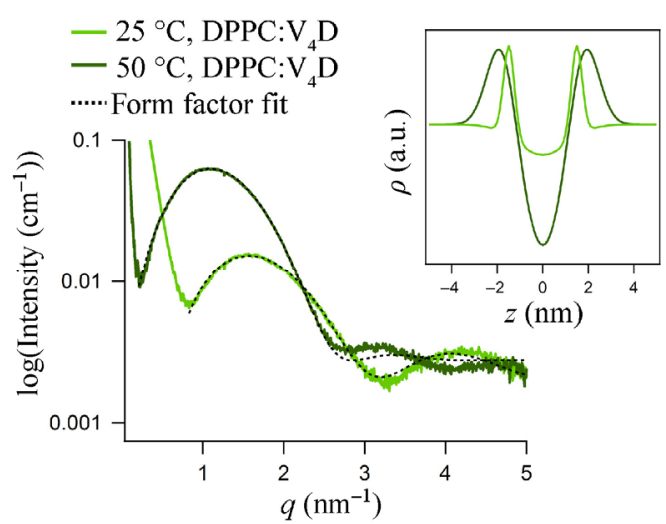

Figure 10 Electron bilayer density distribution of DPPC: $V_{4} D$ at a peptide concentration of $11 \mathrm{mM}$. At $25^{\circ} \mathrm{C}$, we see a strong interdigitation. At $50{ }^{\circ} \mathrm{C}$, higher flexibility is induced and the interdigitation opens up.

Table 4 Fitting results for pure DPPC (using a bilayer form factor and a PT structure factor) and DPPC: $\mathrm{V}_{4} \mathrm{D}$ (using a single bilayer form factor model)

\begin{tabular}{ccc}
\hline Parameter & Pure DPPC & DPPC: $\mathrm{V}_{4} \mathrm{D}$ \\
\hline$z_{\mathrm{H}}(\mathrm{nm})$ & 2.07 & 1.47 \\
$\sigma_{\mathrm{H}}(\mathrm{nm})$ & 0.3 & 0.3 \\
$\rho_{\mathrm{R}}($ a.u. $)$ & 0.85 & 0.49 \\
$\sigma_{\mathrm{C}}(\mathrm{nm})$ & 0.39 & 1.0 \\
$L_{\mathrm{E}}(\mathrm{nm})$ & 50 & - \\
$\Delta(\mathrm{nm})$ & 0.001 & - \\
$d(\mathrm{~nm})$ & 6.4 & - \\
$d_{\mathrm{HH}}(\mathrm{nm})$ & 4.1 & 2.9 \\
$d_{\mathrm{B}}(\mathrm{nm})$ & 5.3 & 4.1 \\
$d_{\mathrm{W}}(\mathrm{nm})$ & 1.1 & - \\
\hline
\end{tabular}

comprises the peptides $\mathrm{I}_{4} \mathrm{WD}_{2}$ and $\mathrm{V}_{3} \mathrm{D}$ (Fig. 9). The first order maximum was shifted to lower $q$ values, which already indicates larger structures. The overall morphology of the curve suggests only partial interdigitation. The vesicles exhibited a predominant noninterdigitated phase, in combination with a small portion of interdigitated structures [44]. In addition, we see that these two samples contained a peak at the very small-angle regime $\left(q=0.3-0.4 \mathrm{~nm}^{-1}\right)$. This might be due to interparticle interactions. However, whether this contribution arises from peptide superstructures or lipid-peptide mixed vesicles remains elusive.

A scattering curve that clearly stood out is DPPC mixed with $\mathrm{L}_{4} \mathrm{WD}_{2}$ (Fig. 9, top). It displayed quasiBragg peaks up to high orders. As can be seen in Fig. 11, 


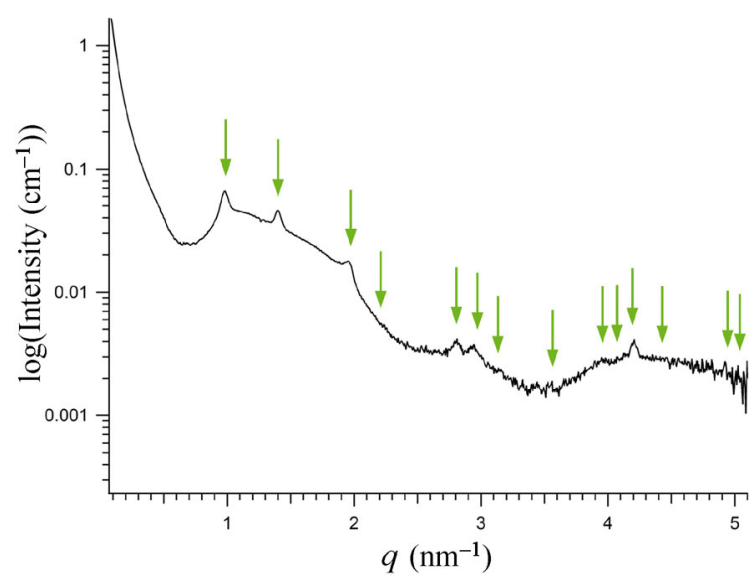

Figure 11 Relating the scattering curve of DPPC: $\mathrm{L}_{4} \mathrm{WD}_{2}(11 \mathrm{mM})$ to a square-packed cylinder lattice. The green arrows show the expected peak positions, which overlap with the Bragg peaks of the experimentally determined scattering curve.

a first try to relate the structure to a lattice type resulted in a very good match with cylinders packed in a square lattice $(P 4 / \mathrm{mm})$ [45]. The predicted peak positions (Fig. 11, green arrows) overlapped with maxima at the experimentally determined scattering curve. However, this structure needs to be characterized in detail in a subsequent study.

3.2.2.2 SAXS analysis of lipid:peptide mixed systems at high peptide concentrations (11 $\mathrm{mM}$ ) and $50{ }^{\circ} \mathrm{C}$

Above the lipid phase transition temperature, the scattering curves showed in general a higher uniformity, nevertheless with subtle differences between the individual peptides (see Fig. 9, where the experimental scattering curves are black dotted lines and the respective fits are represented by light green curves). The first order maximum was shifted to smaller angles, which indicates larger structures. Indeed, when fitting the curves with a single bilayer form factor model, we saw that the tight interdigitation seen at $25^{\circ} \mathrm{C}$ opened up and $d_{\mathrm{HH}}$ values increased. Nevertheless, we still expect a small contribution from interdigitated parts, similar to DPPC: $\mathrm{I}_{4} \mathrm{WD}_{2}$ and DPPC: $\mathrm{V}_{3} \mathrm{D}$ samples at $25^{\circ} \mathrm{C}$. Table 5 summarizes the obtained fitting parameters.

\section{Discussion}

The molecular interactions that lead to the formation of self-assembled supramolecular peptide structures include hydrophobic interactions between tail residues, electrostatic interactions between charged headgroups, chiral dipole-dipole interactions, $\pi-\pi$ stacking, hydrogen bonds, nonspecific van der Waals interactions, and repulsion due to steric hindrances. Even though extensive research has been carried out to relate peptide sequence to structure, it is still challenging to derive general rules for peptide self-assembly, as all the aforementioned forces are balanced amongst each other in a fine interplay. Understanding the peptides' interaction with lipids is even more difficult.

In this systematic study, we aimed to elucidate which sequence or structure components are essential for self-assembly into supramolecular structures and if variations of these components are directly linked to

Table 5 Fitting results for pure DPPC (using a bilayer form factor and a MCT structure factor) and DPPC:peptides (using a single bilayer form factor model) at $50{ }^{\circ} \mathrm{C}$

\begin{tabular}{ccccccccc}
\hline Parameter & Pure DPPC & DPPC: $\mathrm{V}_{4} \mathrm{D}$ & DPPC: $\mathrm{V}_{4} \mathrm{WD}$ & $\mathrm{DPPC}: \mathrm{V}_{4} \mathrm{WD}_{2}$ & DPPC: $\mathrm{V}_{4} \mathrm{D}_{2}$ & DPPC: $\mathrm{I}_{4} \mathrm{WD}_{2}$ & DPPC: $\mathrm{V}_{3} \mathrm{D}$ & DPPC: $_{4} \mathrm{WD}_{2}$ \\
\hline$z_{\mathrm{H}}(\mathrm{nm})$ & 1.87 & 1.77 & 1.76 & 1.85 & 1.86 & 1.91 & 1.81 & 1.69 \\
$\sigma_{\mathrm{H}}(\mathrm{nm})$ & 0.30 & 0.42 & 0.40 & 0.34 & 0.30 & 0.24 & 0.45 & 0.37 \\
$\rho_{\mathrm{R}}($ a.u. $)$ & 0.97 & 1.15 & 0.73 & 1.07 & 0.92 & 0.77 & 1.09 & 0.73 \\
$\sigma_{\mathrm{C}}(\mathrm{nm})$ & 0.66 & 0.73 & 1.14 & 0.65 & 0.66 & 0.68 & 0.82 & 1.20 \\
$L_{\mathrm{E}}(\mathrm{nm})$ & 108 & - & - & - & - & - & - & - \\
$\eta$ & 0.081 & - & - & - & - & - & - & - \\
$d(\mathrm{~nm})$ & 6.5 & - & - & - & - & - & - & - \\
$d_{\mathrm{HH}}(\mathrm{nm})$ & 3.7 & 3.6 & 3.5 & 3.7 & 3.7 & 3.8 & 3.6 & 3.4 \\
$d_{\mathrm{B}}(\mathrm{nm})$ & 4.9 & 5.2 & 5.1 & 5.0 & 4.9 & 4.8 & 5.4 & 4.9 \\
$d_{\mathrm{W}}(\mathrm{nm})$ & 1.6 & - & - & - & - & - & - & - \\
\hline
\end{tabular}


interactions with lipid molecules. First, we have a closer look at pure peptide systems and features that drive the self-assembly process.

\subsection{Hydrophile-lipophile ratio}

Electrostatic repulsion of charged residues is the most important counteracting force to the hydrophobic attraction of tail residues. The hydrophile-lipophile balance determines whether peptide self-assembly is generally possible or restricted. This was best observed when comparing the peptides $V_{3} D, V_{4} D_{2}$, and $V_{4} D . V_{3} D$ and $\mathrm{V}_{4} \mathrm{D}_{2}$ do not self-assemble into supramolecular structures for a wide concentration regime. We suggest that three hydrophobic valines are not able to balance the electrostatic repulsion of one aspartic acid residue $\left(\mathrm{V}_{3} \mathrm{D}\right)$, and likewise, four valines are not able to balance the electrostatic repulsion of two aspartic acid residues $\left(\mathrm{V}_{4} \mathrm{D}_{2}\right)$. In contrast, $\mathrm{V}_{4} \mathrm{D}$ has only $20 \%$ charged residues. The peptide is still soluble, and in addition it is able to self-assemble into supramolecular structures.

Thus, for these simple structures exclusively composed of hydrophobic valines and hydrophilic aspartic acids, the following rule of thumb was established: Not more than $20 \%-25 \%$ of the peptide's total number of residues may have the same charge because then self-assembly is hindered due to electrostatic repulsion.

\subsection{Hydrophobicity and steric considerations}

By replacing all valines in $\mathrm{V}_{4} W D_{2}$ with the amino acids leucine and isoleucine, we were able to compare three peptides that were very close in sequence but varied in their level of hydrophobicity. Despite their similarity on the molecular level, they displayed different characteristics in their supramolecular structures as well as in their lipid-interaction profile. These differences likely arise from their differences in hydrophobicity. As a rule of thumb, the more hydrophobic a peptide is, the lower its CAC is. We have seen that this general statement does not strictly apply anymore when the variations in hydrophobicity are as subtle as in our experiments. $\mathrm{V}_{4} \mathrm{WD}_{2}$ has the highest $\mathrm{CAC}$ amongst the three peptides but is also the most hydrophobic one. Earlier studies have shown that this peptide assembles only into loosely packed aggregates [33] and at very high concentrations (50-75 mM) into ordered lamellar structures. Many hydrophobicity scales [34, 36, 46] rank isoleucine and leucine as less hydrophobic than valine, and structure formation appeared easier for peptides containing these two residues. The steric arrangement of the amino acid side-chains also might influence structure formation. The only difference between leucine and isoleucine is the position of one methyl group. Hence, this little variation has a huge impact on the supramolecular level. However, this characteristic cannot be seen uncoupled from hydrophobicity. Therefore, no general statement on the sole influence of sterics can be given.

\subsection{Tryptophans}

We posed ourselves the question whether tryptophancontaining peptides form different supramolecular structures than peptides without tryptophan due to their ability of $\pi-\pi$ stacking. Neither with SAXS nor with ATR-FTIR spectroscopy could structural characteristics be solely attributed to either tryptophancontaining peptides or tryptophan-lacking peptides. However, an influence of tryptophan could be observed when peptides were mixed with DPPC. These peptides showed a small trend towards facilitated induction of ULV formation at low concentrations (1.1 mM). Tryptophan has a known propensity to intercalate into bilayer interfaces [47] and thus might facilitate the peptide's interaction with DPPC.

\subsection{Peptides induce the formation of ULVs, which show temperature-dependent interdigitation}

When looking at the power of individual peptides to interact with DPPC, we have seen that the majority of peptides at high concentrations lead to the formation of ULVs. The fine structure of the derived ULVs depends on peptide sequence and temperature. The transformation of pure DPPC into various phases as a function of temperature is well known, and the concept may be partly applied also to lipid-peptide mixed systems. At $25^{\circ} \mathrm{C}$, pure DPPC displays a gel phase $\left(\mathrm{L}_{\beta}{ }^{\prime}\right)$, with tilted hydrocarbon chains. Upon heating, DPPC finally changes into the $\mathrm{L}_{\alpha}$ phase, with hydrocarbon chains in a molten state, leading to an increase in the lamellar repeat distance of MLVs but a decrease in the bilayer thickness $d_{\mathrm{HH}}$ [42]. However, 
the presence of peptides leads to a highly rigid packing at $25^{\circ} \mathrm{C}$ and interdigitated structures, which might change the tilting and packing of hydrocarbon chains [44]. Upon heating, we suggest a peptide- and temperature-induced higher flexibility and motility of the hydrocarbon chains, which leads to the observed increase in bilayer thickness.

\subsection{Peptide-induced bicelle formation}

Samples of $55 \mathrm{mM}$ DPPC with $1.1 \mathrm{mM} \mathrm{V} \mathrm{V}_{4} \mathrm{D}$ contained bicelle-like structures. Conventionally, bicelles are discoidal particles composed of long-chain lipids (e.g., 1,2-dimyristoyl-sn-glycero-3-phosphocholine (DMPC)) and short-chain lipids (e.g., 1,2-diheptanoyl-sn-glycero3-phosphocholine (DHPC)). DMPC forms the bilayer region, whereas DHPC forms a surrounding belt $[43,48]$. Instead of DHPC, detergents and bile-salt derivatives have also been used $[49,50]$. To the best of our knowledge, this is the first time that peptideinduced bicelle formation is reported. When speaking of lipid-peptide-mixed systems, similar structures are often described by the term "nanodisc". However, what distinguishes our structures from nanodiscs? Nanodiscs are defined as patches of a lipid bilayer surrounded by amphipathic helices of proteins or peptides [51]. Because $\mathrm{V}_{4} \mathrm{D}$ contains only 5 amino acid residues, we assume that it does not attain the critical length that renders helix formation possible. Thus, we believe that the term "bicelle" is more appropriate to describe our derived structures. Whether they are equally suited for membrane protein crystallography applications or NMR studies [49, 50,52] (and whether they are also magnetically orientable) could be approached in future experiments.

\subsection{The DPPC environment changes the local peptide concentration}

It appears that the DPPC environment influences the local peptide concentration and thus structure. When mixed with DPPC, $11 \mathrm{mM} \mathrm{V}_{4} \mathrm{D}$ exhibited clearly pronounced long tapes. Similar structures within the pure peptide samples were only observed by TEM at concentrations above $20 \mathrm{mM}$. Therefore, we assume that DPPC acts as a solubility-reducing agent on peptides. It changes the local microenvironment by removing solvent from the peptide and thus leads to an effective higher local peptide concentration, which facilitates the peptide self-assembly process.

\subsection{Peptides elicit the formation of a conserved new lamellar phase when mixed with DPPC}

The majority of peptides induced the formation of oligo- or unilamellar vesicles when DPPC was mixed with $11 \mathrm{mM}$ peptide solution. Besides the ULV characteristics, SAXS patterns revealed an additional lamellar phase, which showed a highly conserved lamellar spacing of $4.48 \mathrm{~nm}$ throughout the samples. The amplitudes of these peaks were quite weak, so only a very limited fraction of structures was involved. We posed ourselves the question of how this new lamellar phase can be explained and whether it originates from the peptide-, lipid-, or a mixed phase. For many of the samples, we expect supramolecular peptide structures to be present, as $11 \mathrm{mM}$ exceeds the CAC of the peptides. The distance of $4.48 \mathrm{~nm}$ comes very close to the values observed for pure peptide samples ( 4-4.7 nm, Table 2). These were interpreted as the lamellar distances between the individual supramolecular peptide tapes. It is likely that the same or similar peptide superstructures are also present in the peptide-lipid mixed systems. Moreover, for many samples the 4.48-nm lamellar phase remained present when samples were heated to $50^{\circ} \mathrm{C}$, although some peaks were slightly reduced in their amplitude. However, two peptides did not assemble into supramolecular structures, even at high peptide concentrations. Nevertheless, when these two peptides were mixed with DPPC, they also displayed the 4.48 -nm lamellar phase. If this lamellar phase is attributed to a supramolecular peptide structure, it means that the presence of DPPC triggered the selfassembly process for these two peptides. Another explanation for the emergence of the 4.48-nm lamellar phase considers the lipid fraction. One case assumes the formation of lipid-peptide mixed vesicles that show compositional fluctuations within the bilayer. Lipid-rich domains might be alternating with peptiderich domains. However, a thinning within the same bilayer from 6.35 to $4.48 \mathrm{~nm}$ (e.g., $\mathrm{V}_{4} \mathrm{D}_{2}$ and $\mathrm{V}_{4} \mathrm{WD}_{2}$ ) seems very unlikely with respect to bending rigidity. More likely, the samples contained two different fractions of vesicles: a large number of ULVs in 
coexistence with fewer oligolamellar vesicles, both of which showed interdigitation.

\section{Conclusion}

Despite intensive research over the last decades, it is still a challenge to predict the self-assembled supramolecular structure from a given peptide sequence. We designed seven peptides with systematic sequence variations, and although they differed only in a few amino acid residues, they exhibited different selfassembled supramolecular morphologies. We have shown that lamellar structures with high similarity to lipid membranes can be designed and that these peptide membranes offer exciting possibilities for being applied as successfully as their lipid counterparts. Peptide-lipid mixed systems also spontaneously form a variety of nanostructures: We here described interdigitated and non-interdigitated vesicles, bicelles, and cylindrical structures packed in a 2D squared lattice. All of these structures might be promising candidates for next-generation drug- or gene-delivery systems. Our results highlight that amphiphilic designer peptides that were designed to mimic lipid molecules indeed show similar assembly characteristics. In analogy to the plethora of lipid mesophases, many peptide- or lipid-peptide mixed phases are yet to be discovered.

\section{Acknowledgements}

This work has been supported by the Austrian Science Fund (FWF Project No. I 1109-N28 to R. P.). We gratefully acknowledge Elisabeth Pritz for her support and technical guidance with electron microscopy. We thank Hanna Lindermuth and Hans Krebs for technical assistance.

Electronic Supplementary Material: Supplementary material (determination of the critical aggregation concentrations, TEM analysis) is available in the online version of this article at https://doi.org/10.1007/s12274017-1702-4.

Open Access: This article is distributed under the terms of the Creative Commons Attribution 4.0 International
License (http://creativecommons.org/licenses/by/4.0/), which permits unrestricted use, distribution, and reproduction in any medium, provided you give appropriate credit to the original author(s) and the source, provide a link to the Creative Commons license, and indicate if changes were made.

\section{References}

[1] van Meer, G.; de Kroon, A. I. P. M. Lipid map of the mammalian cell. J. Cell Sci. 2011, 124, 5-8.

[2] van Meer, G.; Voelker, D. R.; Feigenson, G. W. Membrane lipids: Where they are and how they behave. Nat. Rev. Mol. Cell Biol. 2008, 9, 112-124.

[3] Tardieu, A.; Luzzati, V.; Reman, F. C. Structure and polymorphism of the hydrocarbon chains of lipids: A study of lecithin-water phases. J. Mol. Biol. 1973, 75, 711-718, IN17-IN19, 719-733.

[4] Luzzati, V.; Husson, F. The structure of the liquid-crystalline phases of lipid-water systems. J. Cell Biol. 1962, 12, 207-219.

[5] Luzzati, V.; Spegt, P. A. Polymorphism of lipids. Nature 1967, 215, 701-704.

[6] Zhao, X. B.; Pan, F.; Xu, H.; Yaseen, M.; Shan, H. H.; Hauser, C. A. E.; Zhang, S. G.; Lu, J. R. Molecular selfassembly and applications of designer peptide amphiphiles. Chem. Soc. Rev. 2010, 39, 3480-3498.

[7] Khoe, U.; Yang, Y. L.; Zhang, S. G. Self-assembly of nanodonut structure from a cone-shaped designer lipid-like peptide surfactant. Langmuir 2009, 25, 4111-4114.

[8] Hamley, I. W. Self-assembly of amphiphilic peptides. Soft Matter 2011, 7, 4122-4138.

[9] Dehsorkhi, A.; Castelletto, V.; Hamley, I. W. Self-assembling amphiphilic peptides. J. Pept. Sci. 2014, 20, 453-467.

[10] Han, S. Y.; Cao, S. S.; Wang, Y. M.; Wang, J. Q.; Xia, D. H.; Xu, H.; Zhao, X. B.; Lu, J. R. Self-assembly of short peptide amphiphiles: The cooperative effect of hydrophobic interaction and hydrogen bonding. Chem.-Eur. J. 2011, 17, 13095-13102.

[11] Kornmueller, K.; Letofsky-Papst, I.; Gradauer, K.; Mikl, C.; Cacho-Nerin, F.; Leypold, M.; Keller, W.; Leitinger, G.; Amenitsch, H.; Prassl, R. Tracking morphologies at the nanoscale: Self-assembly of an amphiphilic designer peptide into a double helix superstructure. Nano Res. 2015, 8, 1822-1833.

[12] Zhao, Y. R.; Deng, L.; Wang, J. Q.; Xu, H.; Lu, J. R. Solvent controlled structural transition of $\mathrm{KI}_{4} \mathrm{~K}$ self-assemblies: From nanotubes to nanofibrils. Langmuir 2015, 31, 12975-12983.

[13] Zhao, Y. R.; Wang, J. Q.; Deng, L.; Zhou, P.; Wang, S. J.; Wang, Y. T.; Xu, H.; Lu, J. R. Tuning the self-assembly of 
short peptides via sequence variations. Langmuir 2013, 29, 13457-13464.

[14] Cenker, Ç. Ç.; Bomans, P. H. H.; Friedrich, H.; Dedeoğlu, B.; Aviyente, V.; Olsson, U.; Sommerdijk, N. A. J. M.; Bucak, S. Peptide nanotube formation: A crystal growth process. Soft Matter 2012, 8, 7463-7470.

[15] Hauser, C. A. E.; Deng, R. S.; Mishra, A.; Loo, Y.; Khoe, U.; Zhuang, F.R.; Cheong, D. W.; Accardo, A.; Sullivan, M. B.; Riekel, C. et al. Natural tri- to hexapeptides self-assemble in water to amyloid $\beta$-type fiber aggregates by unexpected $\alpha$-helical intermediate structures. Proc. Natl. Acad. Sci. USA 2011, 108, 1361-1366.

[16] Yao, Y.; Xue, M.; Chen, J. Z.; Zhang, M. M.; Huang, F. H. An amphiphilic pillar[5]arene: Synthesis, controllable selfassembly in water, and application in calcein release and TNT adsorption. J. Am. Chem. Soc. 2012, 134, 15712-15715.

[17] Yu, G. C.; Ma, Y. J.; Han, C. Y.; Yao, Y.; Tang, G. P.; Mao, Z. W.; Gao, C. Y.; Huang, F. H. A sugar-functionalized amphiphilic pillar[5]arene: Synthesis, self-assembly in water, and application in bacterial cell agglutination. J. Am. Chem. Soc. 2013, 135, 10310-10313.

[18] Zhao, X. J.; Nagai, Y.; Reeves, P. J.; Kiley, P.; Khorana, H. G.; Zhang, S. G. Designer short peptide surfactants stabilize G protein-coupled receptor bovine rhodopsin. Proc. Natl. Acad. Sci. USA 2006, 103, 17707-17712.

[19] Matsumoto, K.; Vaughn, M.; Bruce, B. D.; Koutsopoulos, S.; Zhang, S. G. Designer peptide surfactants stabilize functional photosystem-I membrane complex in aqueous solution for extended time. J. Phys. Chem. B 2009, 113, 75-83.

[20] Ge, B. S.; Yang, F.; Yu, D. Y.; Liu, S.; Xu, H. Designer amphiphilic short peptides enhance thermal stability of isolated photosystem-I. PLoS One 2010, 5, e10233.

[21] Corin, K.; Baaske, P.; Ravel, D. B.; Song, J. Y.; Brown, E.; Wang, X. Q.; Wienken, C. J.; Jerabek-Willemsen, M.; Duhr, S.; Luo, Y.et al. Designer lipid-like peptides: A class of detergents for studying functional olfactory receptors using commercial cell-free systems. PLoS One 2011, 6, e25067.

[22] Wang, X. Q.; Corin, K.; Baaske, P.; Wienken, C. J.; Jerabek-Willemsen, M.; Duhr, S.; Braun, D.; Zhang, S. G. Peptide surfactants for cell-free production of functional $\mathrm{G}$ protein-coupled receptors. Proc. Natl. Acad. Sci. USA 2011, 108, 9049-9054.

[23] Koutsopoulos, S.; Kaiser, L.; Eriksson, H. M.; Zhang, S. G. Designer peptide surfactants stabilize diverse functional membrane proteins. Chem. Soc. Rev. 2012, 41, 1721-1728.

[24] Chen, C. X.; Pan, F.; Zhang, S. Z.; Hu, J.; Cao, M. W.; Wang, J.; Xu, H.; Zhao, X. B.; Lu, J. R. Antibacterial activities of short designer peptides: A link between propensity for nanostructuring and capacity for membrane destabilization. Biomacromolecules 2010, 11, 402-411.
[25] Dehsorkhi, A.; Castelletto, V.; Hamley, I. W.; Seitsonen, J.; Ruokolainen, J. Interaction between a cationic surfactantlike peptide and lipid vesicles and its relationship to antimicrobial activity. Langmuir 2013, 29, 14246-14253.

[26] Fatouros, D. G.; Lamprou, D. A.; Urquhart, A. J.; Yannopoulos, S. N.; Vizirianakis, I. S.; Zhang, S. G.; Koutsopoulos, S. Lipid-like self-assembling peptide nanovesicles for drug delivery. ACS Appl. Mater. Interfaces 2014, 6, 8184-8189.

[27] Briuglia, M.-L.; Urquhart, A. J.; Lamprou, D. A. Sustained and controlled release of lipophilic drugs from a selfassembling amphiphilic peptide hydrogel. Int. J. Pharm. 2014, 474, 103-111.

[28] Karavasili, C.; Spanakis, M.; Papagiannopoulou, D.; Vizirianakis, I. S.; Fatouros, D. G.; Koutsopoulos, S. Bioactive selfassembling lipid-like peptides as permeation enhancers for oral drug delivery. J. Pharm. Sci. 2015, 104, 2304-2311.

[29] Wiradharma, N.; Tong, Y. W.; Yang, Y. Y. Self-assembled oligopeptide nanostructures for co-delivery of drug and gene with synergistic therapeutic effect. Biomaterials 2009, 30, 3100-3109.

[30] Ruan, L. P.; Zhang, H. Y.; Luo, H. L.; Liu, J. P.; Tang, F. S.; Shi, Y. K.; Zhao, X. J. Designed amphiphilic peptide forms stable nanoweb, slowly releases encapsulated hydrophobic drug, and accelerates animal hemostasis. Proc. Natl. Acad. Sci. USA 2009, 106, 5105-5110.

[31] Wu, E. C.; Zhang, S. G.; Hauser, C. A. E. Self-assembling peptides as Cell-interactive scaffolds. Adv. Funct. Mater. 2012, 22, 456-468.

[32] Loo, Y.; Zhang, S. G.; Hauser, C. A. E. From short peptides to nanofibers to macromolecular assemblies in biomedicine. Biotechnol. Adv. 2012, 30, 593-603.

[33] Kornmueller, K.; Lehofer, B.; Meindl, C.; Fröhlich, E.; Leitinger, G.; Amenitsch, H.; Prassl, R. Peptides at the interface: Self-assembly of amphiphilic designer peptides and their membrane interaction propensity. Biomacromolecules 2016, 17, 3591-3601.

[34] Wimley, W. C.; White, S. H. Experimentally determined hydrophobicity scale for proteins at membrane interfaces. Nat. Struct. Biol. 1996, 3, 842-848.

[35] Pepdraw. Peptide Structure [Online]. http://pepdraw.com/ (accessed Mar 17, 2017).

[36] Simm, S.; Einloft, J.; Mirus, O.; Schleiff, E. 50 years of amino acid hydrophobicity scales: Revisiting the capacity for peptide classification. Biol. Res. 2016, 49, 31.

[37] Amenitsch, H.; Rappolt, M.; Kriechbaum, M.; Mio, H.; Laggner, P.; Bernstorff, S. First performance assessment of the small-angle X-ray scattering beamline at ELETTRA. $J$. Synchrotron Radiat. 1998, 5, 506-508.

[38] Hammersley, A. The FIT2D home page [Online]. http:// www.esrf.eu/computing/scientific/FIT2D/ (accessed Mar17, 2017). 
[39] Orthaber, D.; Bergmann, A.; Glatter, O. SAXS experiments on absolute scale with Kratky systems using water as a secondary standard. J. Appl. Crystallogr. 2000, 33, 218-225.

[40] Pabst, G.; Rappolt, M.; Amenitsch, H.; Laggner, P. Structural information from multilamellar liposomes at full hydration: Full q-range fitting with high quality X-ray data. Phys. Rev. E Stat. Phys. Plasmas Fluids Relat. Interdiscip. Topics 2000, 62, 4000-4009.

[41] Pabst, G.; Koschuch, R.; Pozo-Navas, B.; Rappolt, M.; Lohner, K.; Laggner, P. Structural analysis of weakly ordered membrane stacks. J. Appl. Crystallogr. 2003, 36, 1378-1388.

[42] Nagle, J. F.; Tristram-Nagle, S. Structure of lipid bilayers. Biochim. Biophys. Acta 2000, 1469, 159-195.

[43] Yang, P. W.; Lin, T. L.; Hu, Y.; Jeng, U. S. A time-resolved study on the interaction of oppositely charged bicellesimplications on the charged lipid exchange kinetics. Soft Matter 2015, 11, 2237-2242.

[44] Pabst, G.; Danner, S.; Karmakar, S.; Deutsch, G.; Raghunathan, V. A. On the propensity of phosphatidylglycerols to form interdigitated phases. Biophys. J. 2007, 93, 513-525.

[45] Förster, S.; Fischer, S.; Zielske, K.; Schellbach, C.; Sztucki, M.; Lindner, P.; Perlich, J. Calculation of scattering-patterns of ordered nano- and mesoscale materials. Adv. Coll. Int. Sci. 2011, 163, 53-83.

[46] Kyte, J.; Doolittle, R. F. A simple method for displaying the hydropathic character of a protein. J. Mol. Biol. 1982, 157, 105-132.

[47] Yau, W. M.; Wimley, W. C.; Gawrisch, K.; White, S. H. The preference of tryptophan for membrane interfaces. Biochemistry 1998, 37, 14713-14718.

[48] Yang, P.-W.; Lin, T.-L.; Lin, T.-Y.; Yang, C.-H.; Hu, Y.; Jeng, U. S. Packing DNA with disc-shaped bicelles. Soft Matter 2013, 9, 11542-11548.

[49] Sanders, C. R.; Prosser, R. S. Bicelles: A model membrane system for all seasons? Structure 1998, 6, 1227-1234.

[50] Seddon, A. M.; Curnow, P.; Booth, P. J. Membrane proteins, lipids and detergents: Not just a soap opera. Biochim. Biophys. Acta 2004, 1666, 105-117.

[51] Liang, B. Y.; Tamm, L. K. NMR as a tool to investigate the structure, dynamics and function of membrane proteins. Nat. Struct. Mol. Biol. 2016, 23, 468-474.

[52] Matsumori, N.; Murata, M. 3D structures of membraneassociated small molecules as determined in isotropic bicelles. Nat. Prod. Rep. 2010, 27, 1480-1492. 